\title{
BORIS SCHNAIDERMAN: AS ÚLTIMAS CONVERSAS, OS ÚLTIMOS LIVROS...
}

http://dx.doi.org/10.11606/issn.2237-1184.v0i26p97-100

\author{
Aurora Fornoni Bernardini \\ Universidade de São Paulo (USP)
}

Uma das visitas que fiz ao Professor Boris foi em fins de fevereiro de 2011, quando, em animada conversa com ele e com Jerusa Pires Ferreira, falamos, entre outras coisas, de nossas viagens passadas e futuras (um dos sonhos de Boris era visitar Cartagena, na Colômbia, onde eu acabava de estar, por ocasião do XXIII congresso da ALADAA). Trocamos livros há pouco publicados e dele recebi, afetuosamente dedicados, os mais recentes: Encontros, Guenádi Aigui: Silêncio e Clamor, Tradução, ato Desmedido, e falamos do último, ainda em elaboração, de sua autoria: Caderno Italiano.

Entre os livros que eu levei a ele estava Otra historia del formalismo Ruso, de Pau Sanmartin Ortí, que Boris olhou, sopesou e disse: "Bem, se é outra história do formalismo russo, quer dizer que é contrária às anteriores...".

Depois nos falamos em meados de junho: "Vou ser operado no dia 17 ", disse ele, confiante. Desejei-lhe felicidades. Nesse mesmo dia eu embarcaria para uma viagem aos países do Norte, terminando em São Petersburgo que não via há tantos anos. Ao voltar, procurei-o. Disseramme que estava bem, mas que se encontrava no hospital. Deixei-lhe um abraço e um recado de São Petersburgo do qual - pensei - ele haveria de gostar: "O mal da perestroika é que ela trouxe consigo o capitalismo..."

Sua convalescência foi longa, mas - como me disse ele no início de 2016, "Consegui vencer a doença".

O professor Boris: sempre acreditando no futuro. Mesmo na imprevisibilidade da Rússia e torcendo para acontecer o melhor. (Tive ocasião de acentuar esse traço do professor Boris na apresentação que fiz dele e de sua obra por ocasião da outorga do título de professor emérito da USP, em 2002, e publicada na edição de número 67 da Revista da Biblioteca Mário de Andrade.)

A firmeza de suas convicções não o impedia, entretanto, de abrir-se para outras perspectivas. Em seu livro sobre traduções, ensaios e 
lembranças, Tradução, ato desmedido, há vários exemplos disso. Num deles, após citar um trecho de Schleiermacher sobre "a voz da alma", conclui:

Como são belos e estranhos os caminhos da cultura! Francamente, não é fácil encontrar em outro lugar uma argumentação sólida como esta sobre a relação entre o mundo da linguagem herdada e a criação pessoal. É interessante constatar que nós outros, materialistas convictos, temos que receber esta lição de um teólogo protestante alemão, proferida no início do século XIX. (SCHNAIDERMAN, 2011, p.72)

Arraigados também são certos seus hábitos curiosos, como o comentado em seu livro quanto à máquina de escrever:

Estou agora em dúvida sobre a inclusão destas lembranças aqui, mas, afinal, tudo isso se refere à tradução, não podemos desligá-la da vida (ah, Paulo Rónai!). E sem esse lastro de emoções, eu não estaria agora aqui, martelando as teclas de minha Olivetti portátil, que não se fabrica mais no Brasil e cujo tam-tam-tam marca o ritmo destas minhas divagações.

- Escrevi que a tradução é um ato desmedido - dizia Boris -- porque num encontro em Campinas, uma tradutora pediu a palavra e disse que $o$ que basta para uma tradução, mesmo literária, é que ela esteja escrita em português correto. -- E o estilo? E o espírito do original?!-- interrompi eu, insurgindo-me. - Pois é - disse Boris, por isso é que chamei o livro "Tradução, ato desmedido"!

Lembramo-nos, rindo - quanto ao espírito do original - de um episódio que lhe contei por ocasião da co-tradução que eu havia empreendido de $O$ Exército de Cavalaria de Isaac Babel: um dos revisores não queria que eu traduzisse uma expressão por "ela olhou-o com seus olhos de gralha" por não ser a gralha uma ave conhecida no Brasil. - O que ele queria então - perguntou Boris - Olhos de urubu?

Assim é o professor Boris. Sou-lhe grata pelo longo caminho que percorremos juntos - desde aquele longínquo 1969, quando, após eu haver traduzido, por seu intermédio, um texto filosófico russo a pedido de Caio Graco ("O conceito como processo") ele, inesperadamente, convidou-me para ser sua assistente. "Mas eu não sou nativa, professor Boris!", disse eu, surpresa. Ao que ele respondeu: "Não basta ser nativo para ser habilitado". O professor Boris não era homem de fáceis elogios.

Lembro que um dos primeiros livros que ele me recomendou foi $A$ Dialética da Natureza de F. Engels, que eu li na edição da Paz e Terra de 1976. Lendo-o e admirando-o eu me perguntava o porquê dessa recomendação, em particular. Aos poucos, acho que fui descobrindo "Na natureza se aplicam as mesmas leis dialéticas do movimento, leis essas que governam a aparente contingência dos fatos históricos", diz Engels e "As leis da dialética ( 1 - a da transformação da quantidade em qualidade e vice- 
versa; 2 - a da interpenetração dos contrários e 3 - a da negação da negação) são, por conseguinte, extraídas da história da Natureza, assim como da história da sociedade humana". (p. 34, op. cit.) Pois, justamente, o que tanto impressiona nos filmes de Serguei Eisenstein e que vem explicado e exemplificado magistralmente em seu tratado A natureza não indiferente (1947) é a aplicação dessas leis dialéticas do movimento: ele remonta à origem do movimento na biomecânica ou do movimento/crescimento nos troncos das árvores ou nas conchas dos caracóis, estuda o diagrama desse movimento e o projeta em seus filmes, em termos de tempo e espaço. (Tive ocasião de tratar disso mais detalhadamente em "O orgânico e o patético em S.M. Eisenstein" - Revista Kinoruss, $\mathrm{n}^{\circ}$ 66).

E, mutatis mutandis, é isso que faz Leonid Grossman em Dostoiévski artista, após o levantamento exaustivo dos procedimentos artísticos das obras de Dostoiévski: descobre as leis de sua criação. O mesmo faz Victor Chklóvski em relação às obras de Tolstói, o mesmo faz Rudolf Dugánov em (Велимир хлебников - природа творечства) Velímir Khlébnikov: a natureza da criação quanto à poética de Velímir Khlébnikov, etc. etc.: a descoberta $\mathrm{da}(\mathrm{s})$ lei(s) subjacentes às obras, nos leva à descoberta da... estrutura.

Sim, o professor Boris foi um grande adepto do Estruturalismo. Não dos seus prolongamentos em estudos franceses, que, como lamenta Tódorov em A literatura em perigo se dedicam ao levantamento das figuras do discurso e dos procedimentos retóricos sem chegar à síntese (o "sentido" da obra), mas, sim, enquanto continuação das teses dos Formalistas Russos (particularmente de Tyniánov e Jakobson), com seus corolários: a importância dos estudos comparativos contra os sistemas rígidos, o método contrastivo, os traços distintivos, a análise e seu polo oposto: a síntese, as séries (biográfica, histórica, filosófica etc.) que vêm ligadas ao estudo imanente do texto etc. etc. (Tive ocasião de desenvolver este tópico no artigo que dediquei ao prof. Boris publicado pela revista online RUS' v. 8, n. 10 (2017) "Literatura e Estudos Culturais".1

\footnotetext{
${ }^{1}$ Referências bibliográficas citadas pela professora:

ABDALA JÚNIOR, Benjamin. Um mundo coberto de jovens. São Paulo: EDUSP/ Casa Rex, 2016. BERNARDINI, Aurora Fornoni. "Literatura e estudos culturais". In: RUS - Revista de Literatura e Cultura Russa, v. 8, nº 10 (ISSN: 2317-4765). São Paulo: Edição online, 2017.

BERNARDINI, Aurora Fornoni. "O orgânico e o patético em S.M. Eisentein”. Revista Kinoruss n. 6. São Paulo: Editora Kinoruss, 2015.

BERNARDINI, Aurora Fornoni. "A coragem e o equilíbrio - Boris Schnaiderman professor e crítico refratário às paixões súbitas." Revista da Biblioteca Mário de Andrade, n 67. São Paulo: Imprensa Oficial, 2011.

DUGÁNOV, Rudolf. (Велимир хлебников - природа творечства). Velímir Khlébnikov: a natureza da criação. Moscou: Editor Soviético (Советский писатель) 1990.

ENGELS, Friedrich. A dialética da natureza. Rio de Janeiro: Paz e Terra, 1976.
}

99|BORIS SCHNAIDERMAN: Mestre e amigo: recortes 


\section{Adendo - 18 de maio de 2016}

Todos os anos, aos dezessete de maio, costumava visitar o prof. Boris, por ocasião de seu aniversário, ou - quando ele estava em tratamento - deixava-lhe minha lembrança com o porteiro. Semana retrasada, poucos dias antes de seu aniversário e pouco antes de ele cair e fraturar o fêmur, recebi um telefonema, pela manhã. Era o prof. Boris que me anunciava a publicação do livro Um mundo coberto de jovens, onde estava "aquele artigo" que ele me enviara algum tempo antes e que rememorava um acontecimento ocorrido durante a ditadura: sua prisão durante uma aula e sua soltura da qual me coube participar. - Estou com noventa e nove anos - disse-me Boris - e nunca vou esquecer daquele momento.

Fiquei comovida e, de certa forma, orgulhosa, por sua memória haver-se fixado nesse resgate, como comovida e orgulhosa estou agora, por nossas lembranças de um tempo em que ambos éramos jovens terem povoado, até o fim, a mente e o coração de meu querido e generoso mestre.

Aurora Fornoni Bernardini possui graduação em Língua e Literatura Inglesa pela Universidade de São Paulo (1963), graduação em Curso livre de língua russa pela Universidade de São Paulo (1966), mestrado em Letras (Língua e Literatura Italiana) pela Universidade de São Paulo (1970), doutorado em Letras (Literatura Brasileira pela Universidade de São Paulo (1973). É professora titular do DLO-FFLCH da Universidade de São Paulo. Tem experiência na área de Letras, com ênfase em Teoria e Critica Literárias, atuando principalmente nos seguintes temas: Teoria e Critica Literárias, Literatura Russa, Literatura Italiana, Literatura Comparada e Teoria da Narrativa, Semiótica Russa.

GROSSMAN, Leonid. Dostoiévski artista. Trad. Boris Schnaiderman. Rio de Janeiro: Civilização Brasileira, 1967.

ORTÍ, Pau Sanmartín. Otra historia del formalismo ruso. Madrid: Ediciones Lengua de Trapo Sl., 2008.

SCHNAIDERMAN, Boris. Encontros - Boris Schnaiderman. Rio de Janeiro: Azougue Editorial, 2010.

SCHNAIDERMAN, Boris; FERREIRA, Jerusa Pires. Guenádi Aigui: Silêncio e Clamor. São Paulo: Perspectiva, 2010.

SCHNAIDERMAN, Boris. Tradução: ato desmedido. São Paulo: Perspectiva, 2011.

TODOROV, Tzvetan. A literatura em perigo. Rio de Janeiro: Editora Difel, 2009.

100|BORIS SCHNAIDERMAN: Mestre e amigo: recortes 